\title{
Oxybutynin reduces sweating in depressed patients treated with sertraline: a double-blind, placebo-controlled, clinical study
}

This article was published in the following Dove Press journal:

Neuropsychiatric Disease and Treatment

13 September 2012

Number of times this article has been viewed

\author{
Ali Ghaleiha' \\ Leila Jahangard' \\ Zahra Sherafat' \\ Mohammad Ahmadpanah' \\ Serge Brand ${ }^{2}$ \\ Edith Holsboer-Trachsler ${ }^{2}$ \\ Hafez Bajoghli ${ }^{3}$ \\ Mohammad Haghighi' \\ 'Research Center for Behavioral \\ Disorders and Substances Abuse, \\ Hamadan University of Medical \\ Sciences, Hamadan, Iran; ${ }^{2}$ Psychiatric \\ Hospital of the University of Basel, \\ Center for Affective, Stress and \\ Sleep Disorders, University of Basel, \\ Basel, Switzerland; ${ }^{3}$ Psychiatry and \\ Psychology Research Center, Roozbeh \\ Hospital, Tehran University of Medical \\ Sciences, Tehran, Iran
}

Background: Selective serotonin reuptake inhibitors are primarily used in the pharmacological treatment of patients experiencing a major depressive disorder. However, one of the common unwanted effects is excessive sweating or hyperhidrosis. Oxybutynin is an anticholinergic medication which reduces sweating. The aim of this double-blind study was to examine the effect of administration of oxybutynin on subjective sweating in patients treated with sertraline.

Methods: A total of 140 patients experiencing a major depressive disorder (mean age $37.69 \pm 10.44$ years, 86 females [61.4\%]) treated with sertraline (mean dose $83 \mathrm{mg} /$ day) were consecutively enrolled in the study, and all reported excessive sweating as a side effect. Thereafter, the patients were randomly assigned to either an oxybutynin $5 \mathrm{mg} /$ day group or to a placebo group. At the beginning and end of the 2-week trial, the patients completed questionnaires related to sweating and medication-related side effects.

Results: Over time, subjective sweating reduced significantly in the treatment group as compared with the control group. Oxybutynin-induced side effects were uncommon. Relative to male patients, female patients reported less subjective sweating.

Conclusion: Administration of oxybutynin successfully reduced excessive sweating in patients experiencing a major depressive disorder and treated with sertraline. However, possible gender effects should be taken into account.

Keywords: oxybutynin, sweating, sertraline, major depressive disorders

\section{Introduction}

Depression is a recurrent illness requiring use of antidepressants over prolonged periods of time to treat acute and severe episodes and to prevent further episodes of depression. ${ }^{1}$ Over the last 50 years, a variety of antidepressants has been developed, ${ }^{2}$ and, of these, selective serotonin reuptake inhibitors (SSRIs) have been widely used because of their limited side effects. ${ }^{3-6}$ However, unwanted drug effects are often a factor limiting compliance, so tolerability should be carefully considered at the beginning of treatment. Frequent side effects of SSRIs include: headaches, dizziness, sexual dysfunction, bleeding, anorexia, nausea, palpitations, chest pain, muscle pain, and sweating. Sweating, in particular, is one of the commonly reported and most unpleasant side effects. Excessive sweating, termed hyperhidrosis, is a condition caused by hyperactivity of the sweat glands. This hyperactivity may be local or generalized. According to Stahl, ${ }^{7} 10 \%$ of patients using SSRIs reported sweating as an unpleasant side effect, with even higher prevalence rates in patients using sertraline (18.75\%) compared with other SSRIs (13.4\%). Data from an observational Dutch study including 659 patients experiencing a major depressive disorder and using
Correspondence: Mohammad Haghighi Research Center for Behavioral Disorders and Substances Abuse, Farshchian Hospital, Hamadan Hamadan University of Medical Sciences, 12 Honarestan St, Hamadan 65I684874I, Iran

Tel $+988|\quad| 8285015$

$\mathrm{Fax}+988118285015$

Email haghighi@umsha.ac.ir 
sertraline and 592 patients experiencing a major depressive disorder using other SSRIs showed that those using sertraline reported sweating more frequently as an adverse effect than those using other SSRIs. ${ }^{8}$ Moreover, increased sweating may negatively affect patients' quality of life, interfere with daily activities and social and occupational functioning, and result in noncompliance with treatment. ${ }^{9,10}$ Moreover, tolerance normally does not develop, even after a prolonged period of treatment. ${ }^{11}$

To explain excessive sweating with SSRIs, it is claimed that SSRIs do reduce norepinephrine reuptake, which in turn stimulates peripheral receptors. ${ }^{12}$ However, given the differences in chemical structure and specific 5-hydroxytryptamine reuptake inhibition characteristics between the individual SSRIs, these agents also differ in their side effect profiles. ${ }^{3-7}$ In this regard, it has been suggested that sertraline may increase peripheral receptor stimulation. ${ }^{12}$ To reduce excessive sweat gland activity, parasympatholytic agents might be indicated. Oxybutynin acts as an antagonist of muscarinic M-acetylcholine receptors, and a few studies have demonstrated the efficacy of oxybutynin in the treatment of hyperhidrosis in otherwise healthy subjects. ${ }^{13,14}$ Currently, there is very little published research on the treatment of SSRI-induced hyperhidrosis in patients with depression. ${ }^{15,16}$ Therefore, the aim of the present randomized, double-blind, placebo-controlled trial was to investigate the effect of oxybutynin on sweating in patients suffering from major depressive disorder and taking sertraline. Like other investigators, ${ }^{13-17}$ we expected a decreased rate of subjective sweating in patients experiencing a major depressive disorder with oxybutynin (treatment group) as compared with those experiencing a major depressive disorder with placebo (control group).

\section{Methods and materials}

\section{Sample}

A total of 140 patients (mean age $37.69 \pm 10.44$ years, including 86 females [61.4\%]) experiencing a major depressive disorder were consecutively recruited into this double-blind, placebo-controlled randomized clinical trial. Of the 145 patients approached, 140 (96.6\%) took part, whereas five $(3.4 \%)$ were excluded due to adverse effects as described below. Excluded patients did not differ from participants with regard to demographic data or degree of sweating. Sample characteristics are reported in Table 1. Patients in the treatment (oxybutynin) group did not differ from the control group (placebo) in demographics, sertraline dose, or presenting sweating sites. Inclusion criteria were: major depressive disorder as rated by experts according to the Diagnostic and Statistical Manual of Mental Disorders, Fourth Edition, Text Revision; ${ }^{18}$ treatment with sertraline in average doses of 50-100 mg/day for at least 14 days; excessive sweating related to sertraline; physically healthy, ie, no other medical disorder, eg, hypertension, diabetes, or endocrine disorders, such as thyroid disease; and completion of a consent form to participate in the study. Exclusion criteria were psychiatric morbidity; substance abuse; intolerable or dangerous side effects due to consumption of oxybutynin or placebo, such as gastrointestinal discomfort and urinary retention, dry mouth, and double vision (three in the treatment group and two in the placebo group were excluded due to these side effects); refusal to provide written

Table I Demographic data, sertraline dose, and presenting site of sweating for oxybutynin and placebo groups

\begin{tabular}{|c|c|c|c|}
\hline & $\begin{array}{l}\text { Oxybutynin group } \\
(n=66)\end{array}$ & $\begin{array}{l}\text { Placebo group } \\
(n=74)\end{array}$ & Statistics \\
\hline Age (years, mean $\pm S D$ ) & $37.12 \pm 11.47$ & $38.27 \pm 9.47$ & $\mathrm{t}(\mid 38)=0.65, P=0.52$ \\
\hline Height (cm, mean \pm SD) & $166.98 \pm 10.48$ & $165.40 \pm 9.7 \mid$ & $\mathrm{t}(138)=0.86, P=0.39$ \\
\hline Weight $(\mathrm{kg}$, mean $\pm \mathrm{SD})$ & $71.39 \pm 14.07$ & $69.60 \pm 14.57$ & $\mathrm{t}(\mid 38)=0.80, P=0.43$ \\
\hline Body mass index (mean $\pm S D)$ & $25.70 \pm 4.6 \mathrm{I}$ & $25.63 \pm 6.09$ & $\mathrm{t}(138)=0.06, P=0.96$ \\
\hline Gender (male/female; number; & 27 (50\%); 39 (45.3\%) & 27 (50\%); 47 (54.7\%) & $\chi^{2}(\mathrm{df}=\mathrm{I} ; \mathrm{n}=\mathrm{I} 40)=0.29, P=0.59$ \\
\hline \multicolumn{4}{|l|}{ \% within same gender) } \\
\hline Sertraline dose $(\mathrm{mg} /$ day, mean $\pm \mathrm{SD})$ & $89.01 \pm 49.05$ & $77.70 \pm 38.50$ & $\mathrm{t}(138)=1.53, P=0.13$ \\
\hline Duration of sertraline use (days) & $19.66 \pm 26.84$ & $18.75 \pm 25.36$ & $\mathrm{t}(138)=0.21, P=0.84$ \\
\hline \multicolumn{4}{|l|}{ Presenting site of sweating } \\
\hline Whole body & $37(60.7 \%)$ & $24(39.3 \%)$ & $\chi^{2}(\mathrm{df}=4, \mathrm{n}=140)=8.34, P=0.08$ \\
\hline Head and neck & $12(33.3 \%)$ & $24(66.7 \%)$ & \\
\hline Axilla & $8(40 \%)$ & $12(60 \%)$ & \\
\hline Palms & 2 (33.3\%) & $4(66.7 \%)$ & \\
\hline
\end{tabular}

Abbreviation: SD, standard deviation. 
informed consent; pregnancy; and breast-feeding. The study was performed at the Behavioral Disorders and Substance Abuse Research Center in Farshchian Hospital, Hamadan, Iran. All participants were outpatients and provided their written informed consent. The study was approved by the local ethics committee and performed in accordance with the ethical standards laid down in the Declaration of Helsinki.

\section{Procedure}

Using a quasi-randomized approach, the subjects were assigned either to a treatment group (oxybutynin) or to a control group (placebo). Neither patients nor the study nurses or physicians were informed of group assignment. Sampling occurred as follows: 75 red and 75 black chips were put in a ballot box; patients drawing a red chip were assigned to the target group and patients drawing a black chip were assigned to the control group. Sampling continued until a sample of 140 was reached; at this point, there were 66 patients in the active treatment group (47\%) and 74 patients in the control group (53\%).

Oxybutynin $5 \mathrm{mg} /$ day or placebo were given as tablets of identical shape and color, and the packaging of both compounds was likewise identical. The study continued for 2 consecutive weeks. At the beginning of the study, participants completed a questionnaire related to demographic data and presenting site of sweating; at the beginning and end of the study, participants also completed a questionnaire related to degree of sweating, whereas adverse effects were assessed at the end of the study.

\section{Subjective sweating}

To assess subjective sweating, patients completed the Hyperhidrosis Disease Severity Scale (HDSS), ${ }^{19}$ consisting of four levels of sweating, and participants ticked the box reflecting the respective grade of sweating: grade 1, sweating is never noticeable and causes no trouble in daily activities; grade 2, sweating is tolerable but sometimes interferes in daily activities; grade 3 , sweating is barely tolerable and frequently interferes in daily activities; and grade 4, sweating is never tolerable and permanently interferes in daily activities.

\section{Adverse side effects}

To assess side effects, participants completed a self-report questionnaire, requiring "yes" or "no" responses and related to unwanted side effects such as gastrointestinal complications, sedation, dry mouth, and urinary complications.

\section{Statistical analysis}

By considering the fact that sweating is reported to occur in $18.7 \%$ of patients treated with sertraline ${ }^{7}$ and assuming that oxybutynin is able to reduce sweating by $9 \%$, we included at least 62 patients in each group to achieve a statistical power of 0.80 with a type I error of 0.05 . Comparisons between the treatment and control groups using single $t$-tests and Chi-squared $t$-tests were made with respect to demographic data (age, height, weight, body mass index, gender) and data relating to medication (dose and duration of sertraline intake) and sweating areas (whole body, head and neck, axilla, palms). Differences in sweating levels and adverse effects were calculated using Chisquare tests. To explore possible interactions between gender, time, and treatment, a series of multivariate analyses of variance were performed with the factors of time (measurements before and after treatment), treatment (oxybutynin versus placebo), and gender (female versus male), and mean scores on the HDSS as the dependent variable. The nominal level of significance was set at alpha $\leq 0.05$. All calculations were performed using SPSS version 19.0 for Windows (SPSS Inc, Chicago, IL).

Table 2 Descriptive and inferential statistics of sweating severity before and after two weeks of administration of oxybutynin or placebo

\begin{tabular}{|c|c|c|c|c|c|c|c|c|}
\hline & \multicolumn{3}{|c|}{ Oxybutynin $(n=66)$} & \multicolumn{3}{|c|}{ Placebo $(n=74)$} & \multicolumn{2}{|c|}{ Between-group statistics } \\
\hline & Pre & Post & $\begin{array}{l}\text { Comparison } \\
\text { within group }\end{array}$ & Pre & Post & $\begin{array}{l}\text { Comparison } \\
\text { within group }\end{array}$ & $\begin{array}{l}\text { Pre; } \\
\text { comparison } \\
\text { between groups }\end{array}$ & $\begin{array}{l}\text { Post; } \\
\text { comparison } \\
\text { between groups }\end{array}$ \\
\hline Statistics & & & $\begin{array}{l}X^{2}(d f=6, \\
N=66)=|8.7|, \\
P=0.005\end{array}$ & & & $\begin{array}{l}X^{2}(d f=6 \\
N=74)=50.23 \\
P=0.000\end{array}$ & $\begin{array}{l}X^{2}(d f=2, \\
N=\mid 40)=2.8 I \\
P=0.25\end{array}$ & $\begin{array}{l}X^{2}(d f=3 \\
N=140)=9.07 \\
P=0.03\end{array}$ \\
\hline \multicolumn{9}{|c|}{ Severity of sweating } \\
\hline Grade I & $0(0 \%)$ & $36(54.5 \%)$ & & $0(0 \%)$ & $26(35.1 \%)$ & & & \\
\hline Grade 2 & 27 (40.9\%) & 25 (37.9\%) & & 38 (5I.4\%) & $30(40.5 \%)$ & & & \\
\hline Grade 3 & 21 (3I.8\%) & $4(6.1 \%)$ & & $24(32.4 \%)$ & $13(17.6 \%)$ & & & \\
\hline \multirow[t]{2}{*}{ Grade 4} & $18(27.3 \%)$ & $\mathrm{I}(\mathrm{I} .5 \%)$ & & $12(16.2 \%)$ & $5(6.8 \%)$ & & & \\
\hline & $66(100 \%)$ & $66(100 \%)$ & & $74(100 \%)$ & 74 (100\%) & & & \\
\hline
\end{tabular}


Table 3 Sweating severity according to time (before versus after treatment), group (oxybutynin versus placebo), and gender (males versus females)

\begin{tabular}{|c|c|c|c|c|c|c|c|c|}
\hline & \multicolumn{4}{|c|}{ Oxybutynin } & \multicolumn{4}{|l|}{ Placebo } \\
\hline & \multicolumn{2}{|l|}{ Pre } & \multicolumn{2}{|l|}{ Post } & \multicolumn{2}{|l|}{ Pre } & \multicolumn{2}{|l|}{ Post } \\
\hline & Male & Female & Male & Female & Male & Female & Male & Female \\
\hline & $(n=27)$ & $(n=39)$ & $(n=27)$ & $(n=39)$ & $(n=27)$ & $(n=47)$ & $(n=27)$ & $(n=47)$ \\
\hline & $M(S D)$ & $M(S D)$ & $M(S D)$ & $M(S D)$ & $M(S D)$ & $M(S D)$ & $M(S D)$ & $M(S D)$ \\
\hline Mean & $3.04(0.90)$ & $2.74(0.75)$ & I.78 (0.75) & I.38 (0.59) & $3.04(0.7 I)$ & $2.43(0.68)$ & $2.15(0.82)$ & $\mathrm{I} .85(0.93)$ \\
\hline HDSS scores & & & & & & & & \\
\hline
\end{tabular}

Abbreviations: HDSS, Hyperhidrosis Disease Severity Scale; M, mean; SD, standard deviation.

\section{Results}

\section{Sweating at the beginning and end of the study}

Table 2 provides a descriptive overview of the distribution of the severity of sweating as determined by the HDSS score at the beginning of the study and 2 weeks later for the treatment and control groups. At the beginning of the study, the severity of sweating did not differ significantly between the treatment and control groups. At the end of the study, sweating improved significantly in the treatment compared with the control group. Single within-group comparisons revealed that the severity of sweating decreased significantly in both the treatment and control groups after treatment.

\section{Influence of time, group, and gender on subjective sweating}

To compare possible time, group, and gender interactions further, HDSS means were calculated and used as the dependent variable, while time (before versus after treatment), group (treatment versus control group) and gender (male versus female) were introduced as independent variables (Table 3).

Multivariate analyses of variance revealed that mean HDSS scores decreased significantly over time (F[1, 136] 274.11, $P=0.000, \eta^{2}=0.668$ ), and that female patients $(2.10 \pm 0.07)$ had significantly lower scores $(F[1,136]$ 11.18, $\left.P=0.001, \eta^{2}=0.076\right)$ compared with male patients $(2.50 \pm 0.09)$. Contrary to the results above, when introducing gender as a further factor, no significant mean differences were found between the treatment and control groups $\left(\mathrm{F}[1,136] 1.18, P=0.28, \eta^{2}=0.009\right)$. Furthermore, neither time by gender nor time by gender by group interactions were significant (Fs $<2.80 P \mathrm{~s}>0.10$ ). However, the time by group interaction was statistically significant $\left(\mathrm{F}[1,136] 21.95, P=0.000, \eta^{2}=0.139\right.$; see Figure 1), with greater improvement in the treatment group than in the control group.

\section{Adverse effects}

Table 4 shows the descriptive and inferential statistics concerning adverse effects (gastrointestinal complications, sedation, dry mouth, urinary complications) in both groups. No significantly increased reports of adverse effects were observed in the group treated with oxybutynin compared with the control group. Descriptively, dry mouth and urinary complications were more often reported in the treatment group than in the control group ( $4.4 \%$ versus $0 \%)$.

\section{Discussion}

The key findings of the present double-blind, randomized, clinical study of the effects of oxybutynin on sweating in patients with major depressive disorder treated with sertraline were that, compared with placebo, oxybutynin decreased subjective sweating over time, few adverse effects were reported, and female patients reported a greater decrease in sweating than male patients, irrespective of treatment allocation.

We expected a decreased rate of subjective sweating in patients experiencing a major depressive disorder treated with oxybutynin as compared with placebo, and the data we obtained fully supported this expectation. Therefore, our

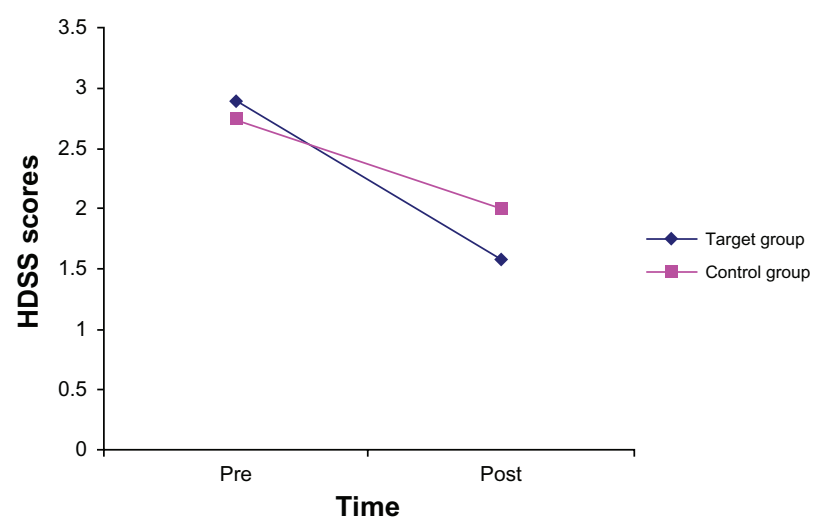

Figure I Hyperhidrosis Disease Severity Scale scores decreased over time, with a greater decrease in the oxybutynin group than in the placebo group (significant time by group interaction $\left.\left[\mathrm{F}(\mathrm{I}, 136) 21.95, P=0.000, \eta^{2}=0.139\right]\right)$. 
Table 4 Adverse effects in the oxybutynin and placebo groups

\begin{tabular}{|c|c|c|c|c|c|}
\hline & \multicolumn{2}{|c|}{ Oxybutynin $(n=66)$} & \multicolumn{2}{|c|}{ Placebo $(n=74)$} & \multirow[t]{2}{*}{ Statistics } \\
\hline & Yes & No & Yes & No & \\
\hline Gastrointestinal complications & $7(10.6 \%)$ & 59 (89.4\%) & $6(8.1 \%)$ & 68 (91.9\%) & $\chi^{2}(\mathrm{df}=\mathrm{I}, \mathrm{N}=\mathrm{I} 40)=0.26, P=0.6 \mathrm{I}$ \\
\hline Sedation & $0(0 \%)$ & $66(100 \%)$ & $0(0 \%)$ & $74(100 \%)$ & - \\
\hline Dry mouth & $3(4.4 \%)$ & $63(95.6 \%)$ & $0(0 \%)$ & $74(100 \%)$ & $\chi^{2}(\mathrm{df}=\mathrm{I}, \mathrm{N}=140)=3.44, P=0.10^{\mathrm{a}}$ \\
\hline Urinary complications & $3(4.4 \%)$ & $63(95.6 \%)$ & $0(0 \%)$ & $74(100 \%)$ & $\chi^{2}(\mathrm{df}=\mathrm{I}, \mathrm{N}=140)=3.44, P=0.10^{\mathrm{a}}$ \\
\hline
\end{tabular}

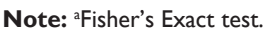

results are in line with those reported by previous investigators, ${ }^{13-16}$ although the present findings add to the literature in an important way in that data were derived from a doubleblind randomized study, which usually does provide unbiased and more reliable data. Moreover, given that sweating is often observed as an unpleasant side effect of SSRIs, in particular sertraline,${ }^{8}$ administration of oxybutynin might be considered to relieve unpleasant sweating and to improve quality of life. ${ }^{9,10}$ In this regard, possible side effects of oxybutynin turned out to be descriptively observable (see Table 4), although statistically these side effects were no more frequent than in the control group.

Despite these encouraging findings, several considerations argue against excessive generalization of the results and favor their cautious interpretation. First, although the sample size was quite large, the inclusion and exclusion criteria were such that findings might not be able to be generalized to older patients experiencing a major depressive disorder or other comorbid diseases, or to inpatients. Second, we note that within the observation time of 2 weeks, sweating was also decreased in the control group receiving placebo. This observation was unexpected, and the underlying physiological and psychological mechanisms remain unclear, although it is conceivable that favorable expectations may have been responsible for this result. Moreover, it is also conceivable that antidepressant treatment per se reduced symptoms of depression and anxiety, thereby leading to a general downregulation of the psychophysiological system. In this respect, sertraline is known to reduce both symptoms of depression and anxiety. Third, we note that the amount of sweating reported was different between female and male patients. Again the underlying physiological and psychological mechanisms were not assessed, but we believe that future research should take into account a possible genderrelated bias. Fourth, only patients willing and able to follow the study protocol were assessed, so a positive selection bias cannot be excluded. Fifth, no psychometric data regarding severity of depression or changes in depression severity were assessed, and investigating the degrees of symptoms might have given further insight into the relationship between symptom severity, response to pharmacological treatment, and sweating. Therefore, future research should assess both patient ratings and clinician ratings of depressive symptoms. Sixth, factors influencing the degree of sweating such as outdoor activities, vocational pursuits, and similar were not assessed. Seventh, the degree of sweating was exclusively assessed by subjective patient judgments, so future research might also introduce objective measurements. ${ }^{20}$ Lastly, the entire pattern of results might have been due to other latent as yet unassessed variables. Future research might include additional physiological and psychological assessments as well as, for instance, a comparison between different SSRIs.

\section{Acknowledgment}

The present paper is based on the doctoral thesis completed by Zahra Sherafat. We thank Nick Emler (Surrey, UK) for proofreading the manuscript.

\section{Disclosure}

The authors report no conflicts of interest in this work.

\section{References}

1. Sadock BJ, Sadock VA. Synopsis of Psychiatry. Philadelphia, PA: Lippincott Williams and Wilkins; 2007.

2. Spiegel R. Psychopharmacology. An Introduction. 4th ed. Chichester, UK: John Wiley \& Sons; 2003.

3. Reid IC, Stewart CA. How antidepressants work: new perspectives on the pathophysiology of depressive disorder. Br J Psychiatry. 2001;178: 299-303.

4. Stahl SM. Basic psychopharmacology of antidepressants. Part 1: Antidepressants have seven distinct mechanisms of action. $J$ Clin Psychiatry. 1998;59:5-14.

5. Stahl SM. Selecting an antidepressant by using mechanism of action to enhance efficacy and avoid side effects. J Clin Psychiatry. 1998;59: 23-29.

6. Thase ME, Koenig AM. First-line pharmacotherapies for depression what is the best choice? Pol Arch Med Wewn. 2009;119:478-485.

7. Stahl SM. Placebo-controlled comparison of the selective serotonin reuptake inhibitors citalopram and sertraline. Biol Psychiatry. 2000;48:894-901.

8. Meijer WE, Heerdink ER, van Eijk JT, Leufkens HG. Adverse events in users of sertraline: results from an observational study in psychiatric practice in The Netherlands. Pharmacoepidemiol Drug Saf. 2002;11: 655-662. 
9. Keller MB, Hirschfeld RM, Demyttenaere K, Baldwin DS. Optimizing outcomes in depression: focus on antidepressant compliance. Int Clin Psychopharmacol. 2002;17:265-271.

10. Kim WO, Kil HK, Yoon KB, Yoo JH. Treatment of generalized hyperhidrosis with oxybutynin in post-menopausal patients. Acta Derm Venereol. 2010;90:291-293.

11. Mavissakalian MR, Perel JM. The side effects burden of extended imipramine treatment of panic disorder. J Clin Psychopharmacol. 2000;20:547-555.

12. Cheshire WP, Fealey RD. Drug-induced hyperhidrosis and hypohidrosis: incidence, prevention, and management. Drug Saf. 2008;31:109-126.

13. Stolman LP. Treatment of hyperhidrosis. Dermatol Clin. 1998;16: 863-869.

14. Tupker RA, Harmsze AM, Deneer VH. Oxybutynin therapy for generalized hyperhidrosis. Arch Dermatol. 2006;142:1065-1066.

15. Tupker RA, Harmsze AM, Deneer VH. Oxybutynin therapy for generalized hyperhidrosis. Arch Dermatol. 2006;142:1065-1066.
16. Mijnhout GS, Kloosterman H, Simsek S, Strack van Schijndel RJM, Netelenbos JC. Oxybutynin: dry days for patients with hyperhidrosis. Neth J Med. 2006;64:326-328.

17. Grootens KP. Oxybutynin for antidepressant-induced hyperhidrosis. Am J Psychiatry. 2001;168:330-331.

18. American Psychiatric Association. Diagnostic and Statistical Manual of Mental Disorders, Fourth Edition, Text Revision. Washington, DC: American Psychiatric Association; 2000.

19. Kowalski JW, Eadie N, Dagget S, Lai PY. Validity and reliability of the Hyperhidrosis Disease Severity Scale (HDSS). [Poster P198]. Presented at the 62nd Annual Meeting of the American Academy of Dermatology, February 6-10, 2004, Washington, DC.

20. Letada PR, Landers JT, Uebelhoer NS, Shumaker PR. Treatment of focal axillary hyperhidrosis using a long-pulsed Nd:YAG $1064 \mathrm{~nm}$ laser at hair reduction settings. J Drugs Dermatol. 2012;11:59-63.

\section{Publish your work in this journal}

Neuropsychiatric Disease and Treatment is an international, peerreviewed journal of clinical therapeutics and pharmacology focusing on concise rapid reporting of clinical or pre-clinical studies on a range of neuropsychiatric and neurological disorders. This journal is indexed on PubMed Central, the 'PsycINFO' database and CAS.
The manuscript management system is completely online and includes a very quick and fair peer-review system, which is all easy to use. Visit http://www.dovepress.com/testimonials.php to read real quotes from published authors.

Submit your manuscript here: http://www.dovepress.com/neuropsychiatric-disease-and-treatment-journal 